\title{
Diabetes and sesame: an insight about the benefits of sesame (Sesamum indicum L.) in curing diabetes
}

\begin{abstract}
Diabetes in present era has become global as a lot of people are suffering from it including children. The World Health Organization (WHO) has reported that 347 million people worldwide suffer from diabetes, with about 3.4 million people dying in 2004 due to consequences of high fasting blood glucose. Diabetes killed 1.6 million people in 2018, up from less than 1 million in 2000 (WHO, 2018). It is predicted that in 2030, the seventh driving reason for death comprehensively will be diabetes. Diabetes can prompt an assortment of difficulties, including cardiovascular maladies, for example, coronary illness, vascular infection, cerebrovascular sickness, and numerous sorts of visual ailment, for example, retinopathy, nephropathy, and neuropath Sesame has for some time been viewed as a valuable herb. Impacts of sesame in lessening glycemia and improving the diabetes status and its entanglements have for some time been illustrated. In any case, barely any reports propose that sesame can help in improving cardiovascular inconveniences in diabetic patients, and along these lines requires further research.
\end{abstract}

\author{
Volume 8 Issue I - 202 |
}

\author{
Hina Saleem, Hafeez Ahmad Sadaqat, \\ Humera Razzaq \\ Department of Plant Breeding and Genetics, University of \\ Agriculture, Pakistan
}

Correspondence: Hina Saleem, Department of Plant Breeding and Genetics, University of Agriculture, Faisalabad 38040, Pakistan, Tel 03216374764, Email hinah3099@gmail.com

Received: November 19, 2020 | Published: March 23, 2021

Keywords: ailment, cerebrovascular, diabetes, glycemia and sesame

Abbreviations: WHO, World health organization; MHF, mental health foundation; HDL-C, high-thickness lipoprotein; LDL-C, low-thickness lipoprotein; TC, complete cholesterol; SSO, sesame seed oil

\section{Introduction}

Diabetes influences a huge number of individuals around the globe and is a serious ailment that has spread widely. In general, Diabetes is caused when the pancreas doesn't emit the hormone insulin, which is responsible for separating sugar in the body. Saleem et al. ${ }^{1}$ This prompts an increase in the glucose levels and it can be lethal if not dealt with properly. It is where your blood glucose, or glucose, levels are unnecessarily high. Glucose begins from the food that you eat. Insulin is a hormone that empowers the glucose to get into your cells to give them vitality. With type 1 diabetes, your body doesn't make insulin. With type 2 diabetes, the more prevalent and common type, your body doesn't make or use insulin well. Without enough insulin, the glucose stays in your blood. You can similarly have pre-diabetes. This suggests your glucose is higher than normal yet not adequately high enough to be called as diabetes. Having pre-diabetes puts you at a higher peril of experiencing type 2 diabetes. Having an excessive measure of glucose in your blood can cause critical issues. It can hurt your eyes, kidneys, and nerves. Diabetes can moreover cause coronary sickness, stroke and even the need to for the evacuation of appendage. Pregnant women can experience diabetes and this condition in them is known as called gestational diabetes.

It is a metabolic disorder that causes severe issues. Diabetes in present era, has become global as a lot of people are suffering from it including children. The World Health Organization (WHO) has reported that 347 million people worldwide suffer from diabetes, with about 3.4 million people dying in 2004 due to consequences of high fasting blood glucose. Diabetes killed 1.6 million people in 2018, up from less than 1 million in $2000 \mathrm{WHO} .^{2}$ It is predicted that in 2030 , the seventh driving reason for death comprehensively will be diabetes Alwan et al. ${ }^{3}$ Diabetes can prompt an assortment of difficulties, including cardiovascular maladies, for example, coronary illness, vascular infection, cerebrovascular sickness, and numerous sorts of visual ailment, for example, retinopathy, nephropathy, and neuropath UKPDS $^{4}$ Figure 1.

Type 1 diabetes mellitus or T1DM Cell-mediated autoimmune destruction of pancreatic islet beta cells that leads to decreased insulin production Epstein et al. ${ }^{5}$ About just $10 \%$ of total population experiences T1DM, ${ }^{6}$ the danger of death from T1DM is still very high Solteszet al. ${ }^{7}$ At present there is a 3-5\% annual increase in instances of T1DM internationally. In the event that this pattern proceeds, the ratio of instances of T1DM is more likely to increase in European kids younger than 5 years. This ratio is anticipated to by twofold in the range of 2005 and 2020 by $70 \%$. In the United States, around 215,000 individuals whose age is 20 years or more are diagnosed to have diabetes and the quantity of new cases with finding of diabetes is about 1.9 million. It is expressed in $0.26 \%$ of all age groups ADA. ${ }^{8}$

Social care and health care are that are identified with T1DM are a huge burden for the economy of any country Gray et al. ${ }^{9}$ In the developed nations the scenario is quite different as, diabetes is one of the main sources of retinopathy, kidney infection, and foot issues and the primary cause of death from cardiovascular issues, which in turn places a huge burden on the part of their economy Fowler ${ }^{10}$ likewise, an examination from US has indicated that T1DM takes away 5-20 years from a patient's lifespan Narayan et al. ${ }^{11}$ This is like the finding of an European report, which detailed that when a youngster has T1DM, the normalized death rate (SMR) increments up to fourfold. T1DM not just influences economies and the life expectancy of patients, yet in addition aims major mental effects, especially in youths. ${ }^{12-14}$

The improvement of long term microvascular and macrovascular causalities is the fundamental reason for mortality identified with T1DM Fowler. ${ }^{10}$ While testing the proportion of microvascular and intense diabetes and the connection between diabetes span and blood glucose control, Stephenson et al., ${ }^{15}$ found an association among microvascular and intense diabetes and glycemic control Stephenson 
et al. ${ }^{15}$ About $20 \%$ of the diabetic patients die due to myocardial arrest. Macrovascular and microvascular complications damages most of the organs. The following are the main reasons related to macrovascular and microvascular complications in T1DM: reformative factors, including glycemic monitoring, diet, tobacco, puberty, sedentary lifestyle, hypertension and non-reformative factors, including diabetes monitoring and duration, genes, and puberty. Impairment in remodeling of microvasculature related to hyperglycemia is the main indicator and the main factor leading to target organ damage. ${ }^{16-27}$ According to a recent study, $45 \%$ are exposed to at least two factors, $15 \%$ have at least three modifiable risk factors and $86 \%$ of young people suffering from T1DM have at least one risk factor for cardiovascular disease Lin et al.

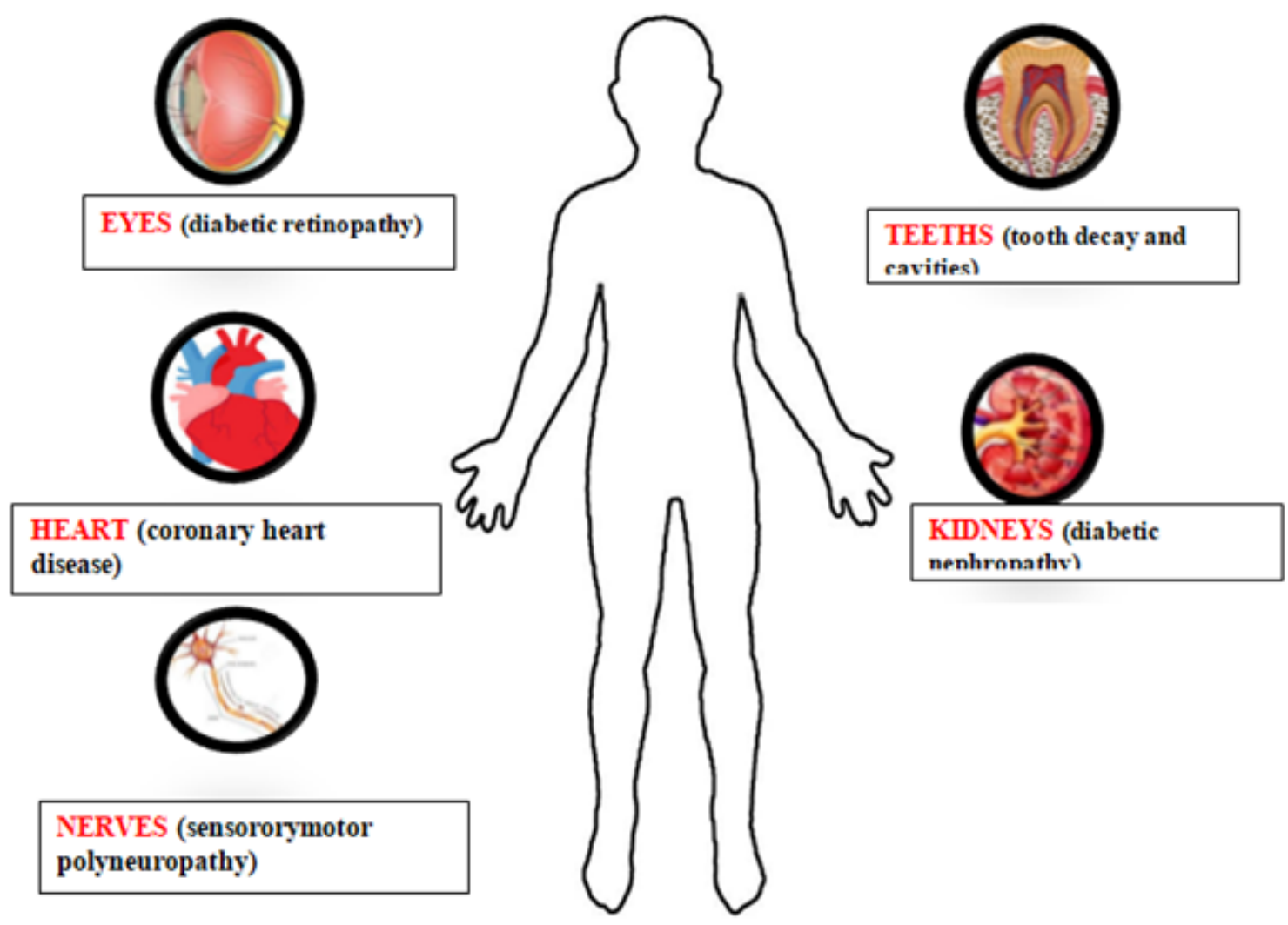

Figure I Diabetes complications.

In 2008, Cheung et al. ${ }^{28}$ concluded in their article that diabetic retinopathy is related to incidence of heart failure. They observed an increase in the development of heart failure in patients with retinopathy (21.6\%) compared to individuals without retinopathy (8.5\%). It is also suggested that awareness supporting knowledge on diabetes plays an important role in lowering the risks of negative psychological impact on people. A recent Danish study indicated that people with the more healthy view on life are less likely to be affected by the stress and have fewer complications as compared to the people with psychological distress. According to mental health foundation a (MHF) person who suffers from extreme anxiety and stress levels have more pronounced chances of developing diabetes and coronary heart failures. Which are highly in turn influenced by lifestyle factors?

\section{Use of sesame as a traditional medicine to cure diabetes}

Since primitive times sesame has been considered as one of the most imminent crop that can be used as a medication, already in specific realms like Aztec and Chinese this was viewed as the unique and rare type of herb with extraordinary advantages. It has brought down the level of heart failure in mouse experiencing diabetes. Relapse of left ventricular hypertrophy in hypertensive rodents has been indicated its effect by decline in size of heart mass, left ventricular thickness, and cardiomyocyte distance across, exhibiting that sesame oil can positively influence the status of cardiovascular hypertrophy in hypertensive rodents Liu et al. In recent experimentation and studies sesame and its liganads have indicated astonishing effect after improving, treating and preventing of diabetes. It has been seen that the consolidated impact of sesame oil and glibenclamide not just will in general reduces the total plasma cholesterol level and blood glucose level, and this fundamentally reduces the condition with type 2 diabetes..$^{29-35}$

Incubation of the beta cells damage is altogether improved by utilization of sesame oil. It likewise improves the insulin, secretion activity and cell vitality. Other than the cardiovascular structure, sesame moreover shows benefits in various forms. Loss of bones due to estrogen need was reduced by oral consumption of diets improved with soybean oil and sesame oil in ovariectomized rodents. Sesame oil and sesamol have also shown additional benefits in treating overwhelming metal poisoning. Amounts of supplements E and $\mathrm{K}$ extended in rat tissue on using sesame seeds and ligands as the standard eating routine. In another examination on the restriction of primary IgE levels in easily affected asthma, sesame oil reduced aspiratory edema and impartial bronchitis; meanwhile the interleukin (IL)- $1 \beta$ and IL-6 levels were generally lessened in bronchoalveolar lavage liquid. ${ }^{36-44}$ 
Sesamin is the dynamic specialist and one of the most plenteous lignans in sesame. It shows an assortment of activities and capacities, and is of much incentive as a pharmaceutical Numerous investigations have exhibited that sesamin has various medical advantages, remembering improvement for fat digestion, cancer prevention agent activity, hypolipidemic action, decrease of cholesterol, calming activity, upgraded power of nutrient $\mathrm{E}$, etc. The recent news about sesame and its control for diabetes as it is found to lower the blood pressure and improved antioxidant status in hypertensive and diabetichypertensive patients. This has created hype in the scientific world that lead to many studies and one of them was carried out by Sankar et al. ${ }^{12}$ The point of their study was to assess the viability of sesame oil with anti-diabetic (glibenclamide) medicine as a blended treatment in mild to moderate diabetic patients for this purpose an experiment was carried. ${ }^{45-52}$

This open name study included sixty type 2 diabetes mellitus patients separated into 3 groups, with dosage of sesame oil $(n=18)$, $5 \mathrm{mg} /$ day (single portion) of glibenclamide $(\mathrm{n}=20)$, or their mix $(n=22)$. The patients were provided with sesame oil [BNB Sesame oil(TM)] aside from glibenclamide group, and prescribed to consume roughly $35 \mathrm{~g}$ of oil/day/individual for cooking, or plate of mixed salad for 60 days. After $12 \mathrm{~h}$-fasting venous blood tests were collected at base line and following 60 days of the test for different biochemical experimentation. ${ }^{53-58}$ The results concluded that: As compared with sesame oil and glibenclamide alone, blended treatment showed an improved anti-hyperglycemic impact with $36 \%$ decrease of glucose $(\mathrm{P}<0.001$ versus before treatment, $\mathrm{P}<0.01$ versus sesame oil monotherapy, $\mathrm{P}<0.05$ versus glibenclamide monotherapy) and $43 \%$ decrease of $\operatorname{HbA}(1 \mathrm{c})(\mathrm{P}<0.001$ versus before treatment, $\mathrm{P}<0.01$ versus sesame oil monotherapy, $\mathrm{P}<0.05$ versus glibenclamide monotherapy) toward the end point. Huge decreases in the plasma TC, LDL-C and TG levels were noted in sesame oil $(20 \%, 33.8 \%$ and $14 \%$ separately versus before treatment) or blend treatments $(22 \%, 38 \%$ and $15 \%$ individually versus before treatment). Plasma HDL-C was essentially improved in sesame oil ( $15.7 \%$ versus before treatment) or blend treatments $(17 \%$ before treatment). Huge $(\mathrm{P}<0.001)$ improvement was seen in the exercises of enzymatic and non-enzymatic cell reinforcements in patients treated with sesame oil and its mix with glibenclamide. ${ }^{59-64}$

Hence it was concluded that Sesame oil showed synergistic impact with glibenclamide and can give a protected and successful alternative for the medication combination that might be exceptionally valuable in clinical practice for the effective improvement of hyperglycemia. Aslam et al.$^{65}$ carried out the study to investigate the protective impact of sesame seed oil (SSO) separated from Til-06 sesame assortment in Sprague-Dawley male rodents against the administration of hypercholesterolemia, the current two-stage study was led. In the main stage, oil was taken out from the sesame seeds (Til-06) and physicochemical examination was completed to discover the substance of oil following by the assessment of the quality ascribes of removed oil. In the subsequent stage, viability was done to check the hyperlipidemic action of sesame seed oil. Haphazardly appropriated twenty (20) rodents into 5 distinct gatherings with four (04) rodents in each gathering and for 60 days took care of as follow; the principal bunch was benefited from a basal eating regimen, while different gatherings were taken care of with 2, 4, 6 and $8 \%$ SSO in addition to basal eating routine. Blood tests were gathered toward the start and end of the examination for biochemical investigation for example lipid profile which incorporates high-thickness lipoprotein (HDL-C), fatty oils (TG), low-thickness lipoprotein (LDL-C), complete cholesterol (TC), and low-thickness lipoprotein (VLDL) and cell reinforcement status. Discoveries of the current investigation show that the oral organization of SSO fundamentally $(\mathrm{P}<0.05)$ improved the cell reinforcement status with lower TC, LDL-C, TG, VLDL-C, and higher HDL-C estimations of hypercholesterolemic rodents.

\section{Great source of fiber}

Sesame seeds are wealthy in fiber and intake of sesame seeds regularly will help in expanding the fiber content in the body. Fiber hinders the assimilation of sugar in the body and henceforth legitimately keeps a mind the glucose levels of the body. Eating fiber rich food, similar to sesame seeds can be truly useful in overseeing diabetes.

\section{Low starch content}

The low starch substance of sesame seeds adds to their advantages for glucose control. Low starch content methods less sugar, which means controlled glucose.

\section{Sesame seeds contain pinoresinol}

Pinoresinol is a compound that can help control glucose by repressing the activity of the chemical maltase. Maltase is a stomach related chemical that separates glucose maltose. Sesame seeds contain pinoresinol, which when represses the breakdown of maltose, can help in controlling sugar.

\section{Rich in cancer prevention agents}

Human experimentations propose that utilization of sesame seeds can build the degree of cancer prevention agent action in your body. Keeping poisons out of your body is a method of keeping your body capacities effective. Cancer prevention agents may put off your danger of creating diabetes, and may likewise improve insulin creation and use in your body.

\section{Sesame seeds increases immunity}

Sesame seeds improve insusceptibility because of their exceptional nutrient substance and accordingly can cure illnesses. Having diabetes can put you in danger of different illnesses additionally, and hence great immunity is essential to battle those sicknesses and help your body be solid.

\section{Conclusion}

Outperforming nephropathy, cardiovascular infections have become the most common difficulties in bringing about high dreariness and death rates in diabetic subjects. Microvascular anomalies in diabetes cause cardiovascular complexities. To limit these intricacies, recognizing early beginning of microvascular illness is fundamental. Also, other hazard factors related with macrovascular sicknesses, for example, diabetic nephropathy, diabetic retinopathy, and diabetic neuropathy require consideration during ailment process monitoring. Numerous examinations have given an assortment of techniques to improving the diabetes status and related confusions, including escalated treatment, siphoning and infusing insulin, hypoglycemia drugs, and placebos. An ebb and flow intrigue is the utilization of regular prescriptions in infection treatment to constrain the unfavorable impacts of compound medications. Customary Chinese prescriptions have a job in such medications, particularly in diabetes. Sesame has for some time been viewed as a valuable herb. Impacts of sesame in lessening glycemia and improving the diabetes status and its entanglements have for some time been illustrated. In any case, barely any reports propose that sesame can help in improving 
cardiovascular inconveniences in diabetic patients, and along these lines requires further research.

\section{Funding}

None.

\section{Acknowledgments}

None.

\section{Conflicts of interest}

The authors declare that they have no conflicts of interest.

\section{References}

1. Saleem H, HA Sadaqat, Sana-e-Mustafa. Sesame (Sesamum indicum L.) a hub of nutrients: strategies towards mitigating the climate change and introducing climate smart agriculture by 2050. SSRG International Journal of Medical Science (SSRG-IJMS). 2019;6(8):23-24.

2. World Health Organization. Diabetes facts. 2013.

3. Alwan A, MacLean DR, Riley LM, et al. Monitoring and surveillance of chronic non-communicable diseases: progress and capacity in highburden countries. Lancet. 2010;376(9755):1861-1868.

4. UK prospective diabetes study (UKPDS). VIII. Study design, progress and performance. Diabetologia. 1991;34(12):877-879.

5. Epstein FH, Atkinson MA, Maclaren NK. The pathogenesis of insulindependent diabetes mellitus. $N$ Engl J Med. 1994;331(21):1428-1436.

6. Atlanta, GA: US Department of health and human services, centers for disease control and prevention; 2011. US Department of health and human services, centers for disease control and prevention. National diabetes fact sheet: national estimates and general information on diabetes and prediabetes in the United States. 2011.

7. Soltesz G, Patterson CC, Dahlquist G. Worldwide childhood type 1 diabetes incidence-what can we learn from epidemiology? Pediatr Diabetes. 2007;8 Suppl 6:6-14.

8. American diabetes association. Data from the 2011 national diabetes fact sheet. Diabetes Stat. 2011:1-4.

9. Gray A, Fenn P, McGuire A. The cost of insulin-dependent diabetes mellitus (IDDM) in England and Wales. Diabet Med. 1995;12(12):10681076 .

10. Fowler MJ. Microvascular and macrovascular complications of diabetes. Clin Diabetes. 2008;26(2):77-82.

11. Narayan KV, Boyle JP, Thompson TJ, et al. Lifetime risk for diabetes mellitus in the United States. JAMA. 2003;290(14):1884-1890.

12. Sankar D, Ali A, Sambandam G, et al. Sesame oil exhibits synergistic effect with anti-diabetic medication in patients with type 2 diabetes mellitus. Clin Nutr. 2011;30(3):351-358.

13. Skrivarhaug T, Bangstad HJ, Stene LC, et al. Long-term mortality in a nationwide cohort of childhood-onset type 1 diabetic patients in Norway. Diabetologia. 2006;49(2):298-305.

14. Ashraff S, Siddiqui MA, Carline TE. The psychosocial impact of diabetes in adolescents: a review. Oman Med J. 2013;28(3):159-162.

15. Microvascular and acute complications in IDDM patients: The EURODIAB IDDM complications study. Diabetologia. 1994;37(3):278285.

16. Boucek P. Diabetic nephropathy/diabetic kidney disease. Vnitr Lek. 2013;59(3):201-203.
17. Ponchiardi C, Mauer M, Najafian B. Temporal profile of diabetic nephropathy pathologic changes. Curr Diabetes Rep. 2013;13(4):592599.

18. Laing SP, Swerdlow AJ, Slater SD, et al. Mortality from heart disease in a cohort of 23,000 patients with insulin-treated diabetes. Diabetologia. 2003;46(6):760-765.

19. Marcovecchio ML, Tossavainen PH, Dunger DB. Prevention and treatment of microvascular disease in childhood type 1 diabetes. $\mathrm{Br} \mathrm{Med}$ Bull. 2010;94:145-164.

20. Dahl-Jørgensen K, Larsen JR, Hanssen KF. Atherosclerosis in childhood and adolescent type 1 diabetes: early disease, early treatment? Diabetologia. 2005;48(8):1445-1453.

21. Mahgoub MA, Abd-Elfattah AS. Diabetes mellitus and cardiac function. Mol Cell Biochem. 1998;180(1-2):59-64.

22. Moore DJ, Gregory JM, Kumah-Crystal YA, et al. Mitigating micro-and macro-vascular complications of diabetes beginning in adolescence. Vas Health Risk Manag. 2009;5:1015-1031.

23. Spinetti G, Kraenkel N, Emanueli C, et al. Diabetes and vessel wall remodelling: from mechanistic insights to regenerative therapies. Cardiovasc Res. 2008;78(2):265-273.

24. Margeirsdottir HD, Larsen JR, Brunborg C, et al. High prevalence of cardiovascular risk factors in children and adolescents with type 1 diabetes: a population-based study. Diabetologia. 2008;51(4):554-561.

25. Silverstein J, Klingensmith G, Copeland K, et al. Care of children and adolescents with type 1 diabetes. A statement of the American diabetes association. Diabetes Care. 2005;28(1):186-212.

26. Wadén J, Forsblom C, Thorn LM, et al. A1C variability predicts incident cardiovascular events, microalbuminuria, and overt diabetic nephropathy in patients with type 1 diabetes. Diabetes. 2009;58(11):2649-2655.

27. Erqou S, Lee CT, Suffoletto M, et al. Association between glycated haemoglobin and the risk of congestive heart failure in diabetes mellitus: systematic review and meta-analysis. Eur J Heart Fail. 2013;15(2):185193.

28. Cheung N, Wang JJ, Rogers SL, et al. Diabetic retinopathy and risk of heart failure. J Am Coll Cardiol. 2008;51(16):1573-1578.

29. Donaghue KC, Chiarelli F, Trotta D, et al. Microvascular and macrovascular complications associated with diabetes in children and adolescents. Pediatr Diabetes. 2009;10(Suppl 12):195-203.

30. American diabetes association. Standards of medical care in diabetes. Diabetes Care. 2012;35(Suppl 1):S11-S63.

31. Kramer CK, Rodrigues TC, Canani LH, et al. Diabetic retinopathy predicts all-cause mortality and cardiovascular events in both type 1 and 2 diabetes meta-analysis of observational studies. Diabetes Care. 2011;34(5):1238-1244.

32. Orchard TJ, Secrest AM, Miller RG, et al. In the absence of renal disease, 20-year mortality risk in type 1 diabetes is comparable to that of the general population: a report from the Pittsburgh epidemiology of diabetes complications study. Diabetologia. 2010;53(11):2312-2319.

33. Lehto S, Rönnemaa T, Pyörälä K, et al. Poor glycemic control predicts coronary heart disease events in patients with type 1 diabetes withou nephropathy. Arterioscler Thromb Vasc Biol. 1999;19(4):1014-1019.

34. Orchard TJ, Olson JC, Erbey JR, et al. Insulin resistance-related factors, but not glycemia, predict coronary artery disease in type 1 diabetes: 10-year follow-up data from the Pittsburgh epidemiology of diabetes complications study. Diabetes Care. 2003;26(5):1374-1379.

35. Libby P, Theroux P. Pathophysiology of coronary artery disease. Circulation. 2005;111(25):3481-3488. 
36. Greenland P, Alpert JS, Beller GA, et al. 2010 ACCF/AHA guideline for assessment of cardiovascular risk in asymptomatic adults: a report of the American college of cardiology foundation/American heart association task force on practice guidelines. J Am Coll Cardiol. 2010;56(25):e50 e103.

37. Nathan DM, Cleary PA, Backlund JY, et al. Intensive diabetes treatmen and cardiovascular disease in patients with type 1 diabetes. $N$ Engl J Med. 2005;353(25):2643-2653

38. Reichard P, Nilsson BY, Rosenqvist U. The effect of long-term intensified insulin treatment on the development of microvascular complications of diabetes mellitus. N Engl J Med. 1993;329(5):304-309.

39. Effect of intensive diabetes treatment on the development and progression of long-term complications in adolescents with insulin-dependent diabetes mellitus: diabetes control and complications trial research group. J Pediatr. 1994;125(2):177-188.

40. Welschen LM, Bloemendal E, Nijpels G, et al. Self-monitoring of blood glucose in patients with type 2 diabetes who are not using insulin: A systematic review. Cochrane Database Syst Rev. 2005;2:CD005060.

41. Fonseca V, Clark NG. Standards of medical care in diabetes response to power. Diabetes Care. 2006;29:476-477.

42. Trimeche A, Selmi Y, Ben Slama F, et al. Effect of protein restriction on renal function and nutritional status of type 1 diabetes at the stage of renal impairment. Tunis Med. 2013;91(2):117-122.

43. Vanninen E, Uusitupa M, Siitonen O, et al. Habitual physical activity, aerobic capacity and metabolic control in patients with newly-diagnosed type 2 (non-insulin-dependent) diabetes mellitus: effect of 1-year diet and exercise intervention. Diabetologia. 1992;35(4):340-346.

44. Delmonte V, Peixoto EM, Poggioli R, et al. Ten years' evaluation of diet, anthropometry, and physical exercise adherence after islet allotransplantation. Transplant Proc. 2013;45(5):2025-2028.

45. Joensen LE, Tapager I, Willaing I. Diabetes distress in type 1 diabetes-a new measurement fit for purpose. Diabet Med. 2013;30(9):1132-1139.

46. Hong YJ, Kim N, Lee K, et al. Korean red ginseng (Panax ginseng) ameliorates type 1 diabetes and restores immune cell compartments. $J$ Ethnopharmacol. 2012;144(2):225-233.

47. Watanabe K, Matsuura K, Gao P, et al. Traditional Japanese Kampo medicine: clinical research between modernity and traditional medicinethe state of research and methodological suggestions for the future. Evid Based Complement Alternat Med. 2011;2011:513842

48. Ikemoto T, Sugimoto K, Takita M, et al. Japanese herbal medicine TJ-48 prevents autoimmune diabetes in NOD mice. Am J Chin Med. 2011;39(4):743-756

49. Li WL, Zheng HC, Bukuru J, et al. Natural medicines used in the traditional Chinese medical system for therapy of diabetes mellitus. $J$ Ethnopharmacol. 2004;92(1):1-22.
50. Li GQ, Kam A, Wong KH, et al. Herbal medicines for the management of diabetes. Adv Exp Med Biol. 2012;771:396-413.

51. Cui TH, Li YY. Treatment of type 2 diabetes mellitus oral Chinese patent medicine literature metrology analysis. Zhongguo Zhong Yao Za Zhi. 2012;37(17):2649-2652.

52. Ceylan-Isik AF, Fliethman RM, Wold LE, et al. Herbal and traditional Chinese medicine for the treatment of cardiovascular complications in diabetes mellitus. Curr Diabetes Rev. 2008;4(4):320-328.

53. Ozkol H, Tuluce Y, Dilsiz N, et al. Therapeutic potential of some plant extracts used in Turkish traditional medicine on streptozocin-induced type 1 diabetes mellitus in rats. $J$ Membr Biol. 2013;246(1):47-55.

54. Liu SX, Chou GC. Review effects of Chinese herbal products on mammalian retinal functions. J Ocul Pharmacol Ther. 1996;12(3):377386.

55. Haidari F, Omidian K, Rafiei H, et al. Green Tea (Camellia sinensis) supplementation to diabetic rats improves serum and hepatic oxidative stress markers. Iran J Pharm Res. 2013;12(1):109-114.

56. Akhani SP, Vishwakarma SL, Goyal RK. Anti-diabetic activity of zingiber officinale in streptozotocin-induced type I diabetic rats. $J$ Pharm Pharmacol. 2004;56(1):101-105.

57. Raman A, Lau C. Anti-diabetic properties and phytochemistry of Momordica charantia L. (Cucurbitaceae). Phytomedicine. 1996;2(4):349362.

58. Shu XS, Lv JH, Tao J, et al. Antihyperglycemic effects of total flavonoids from polygonatum odoratum in STZ and alloxan-induced diabetic rats. $J$ Ethnopharmacol. 2009;124(3):539-543.

59. Miura T, Noda M, Fukunaga T, et al. Hypoglycemic activity of to-kai-san (Chinese medicines) in normal and KK-Ay mice. J Nutr Sci Vitaminol (Tokyo). 1997;43(1):11-17.

60. Liu JP, Zhang M, Wang WY, et al. Chinese herbal medicines for type 2 diabetes mellitus. Cochrane Database Syst Rev. 2004;3:CD003642.

61. Jia W, Gao W, Tang L. Antidiabetic herbal drugs officially approved in China. Phytother Res. 2003;17(10):1127-1134.

62. Liu CT, Periasamy S, Chang CC, et al. Sesame oil therapeutically ameliorates cardiac hypertrophy by regulating hypokalemia in hypertensive rats. JPEN J Parenter Enteral Nutr. 2013;38(6):750-757.

63. Sankar D, Ali A, Sambandam G, et al. Sesame oil exhibits synergistic effect with anti-diabetic medication in patients with type 2 diabetes mellitus. Clin Nutr. 2011;30(3):351-358.

64. Lei H, Han J, Wang Q, et al. Effects of sesamin on streptozotocin (STZ)-induced NIT-1 pancreatic $\beta$-cell damage. Int $J$ Mol Sci. 2012;13(12):16961-16970.

65. Aslam M, Shabbir MA, Pasha I, et al. Protective effect of sesame (sesamum indicum) seed oil against hypercholesterolemic in spraguedawley male rats. Food Sci Technol Campinas. 2020. 